\title{
Is the UK government right that seven day working in hospitals would save 6000 lives a year?
}

\author{
The claim turned out to come from a single study that shows nothing so simple
}

\author{
Martin McKee professor, London School of Hygiene and Tropical Medicine, London, UK
}

On 16 July 2015, Health Secretary Jeremy Hunt used BBC

Radio 4's Today programme to warn the British public that "we have about 6000 avoidable deaths every year in the NHS" and that "lack of senior consultant cover at weekends is one of the critical points." 1

But it subsequently emerged that only one of more than 4000 consultants has opted out of weekend working. ${ }^{2}$ And we do not know whether excess mortality is a consequence of lower quality of care or of some difference in case mix comparing weekend with weekday admissions. The evidence underpinning Hunt's claim has received too little attention.

One reason for the lack of scrutiny was that the Department of Health did not disclose the evidence. The BBC reported, "The 6000 figure ... that was used by the government was from research that has yet to be published." 3

Hunt did refer to a paper published in $2012,{ }^{4}$ but only as background, perhaps reflecting how that study painted a much more complex picture than the one being portrayed.

Consequently, it was a surprise when, on 13 August 2015, in response to freedom of information requests I made, the department said that Hunt's comments had indeed been based on the 2012 paper; the "yet to be published" research received no mention. ${ }^{5}$ We now know that the new study that the Department of Health was referring to is an updated analysis by the same authors that has now been published in The BMJ, ${ }^{6}$ but this was not available to anyone seeking the evidence base at the time the policy was announced, contrary to the code of practice for official statistics. ${ }^{7}$

\section{What did it show?}

Selective extraction from the 2012 paper does support one part of Hunt's statement. If the death rate could be brought down to that seen among patients admitted on a Wednesday there would be fewer deaths because the 30 day mortality rate is $11 \%$ higher among those admitted on Saturdays and 16\% higher on Sundays.

But what about people who are already in hospital at a weekend? They had a significantly reduced risk of dying on a Saturday (5\% less) and Sunday (8\% less). This is presumably because fewer major procedures are taking place, consistent with the observation that mortality often falls when doctors go on strike. ${ }^{8}$ The simplistic solution, to stop major surgery on a few more days each week, has obvious flaws.

The situation is further complicated by the observation that patients admitted on a Sunday who are not emergencies have a $62 \%$ greater risk of dying in the next 30 days than those admitted on a Wednesday (95\% confidence interval $50 \%$ to $75 \%$ ). This may be an example of "confounding by indication," with patients who are at greatest risk admitted early to prepare them for elective surgery. Although the analyses were adjusted for severity to the extent possible by using routine administrative data, the ability to do so is limited without detailed clinical data.

Then there is the matter of attribution. The health secretary describes the excess deaths as "avoidable" and links them to his perception of a lack of consultant cover at weekends. This may be the case for some deaths, but there are many other possibilities. The most obvious is that patients admitted as emergencies at weekends have been clinging on for several days in their own homes or in residential care. The increased risk of death associated with moving frail elderly people is well known, even when the move is not a result of their condition, as with the forced closure of care homes. ${ }^{10}$ It is also possible that the onset of the weekend, when community support services may be difficult to access, may influence the decision by general practitioners to refer for admission or by families to take the patient to an emergency department. Factors such as the level of dehydration in patients, not picked up in routine data, can have a huge effect on subsequent mortality. ${ }^{11}$

The observation that a change to seven day working in stroke services does not necessarily reduce mortality does not help to resolve the issue. ${ }^{12}$ A study of 103 English stroke units found no better 30 day mortality outcomes in units with consultant rounds seven days a week than in those with fewer. It did find a dose-response relation with registered nurse staffing levels at weekends, suggesting that the answer may lie other than with consultants. $^{13}$ 


\section{What would seven day working cost?}

Finally, if we assume that 6000 deaths could be saved by seven day working, the question arises as to how to do this. Many parts of hospitals, such as emergency departments and intensive care units, already work 24 hours a day, seven days a week. There may be other parts that should, but which ones and with what consequences for the rest of the hospital or, more likely, the configuration of hospital networks? Given the challenges of rapidly expanding the consultant workforce, as well as the specialised support that consultants require, staffing levels will inevitably be reduced at other times in the week. And at a time when the NHS faces unprecedented financial pressure, what would seven day working cost? One study suggested that it would exceed the guidelines on cost per quality adjusted life year (QALY) applied by the National Institute for Health and Care Excellence by a factor of between 1.5 and 2.4, or between $£ 339 \mathrm{~m}$ ( $€ 416 \mathrm{~m}$; $\$ 520 \mathrm{~m}$ ) and $£ 831 \mathrm{~m}$ a year. ${ }^{14}$

The government justified the last reorganisation of the NHS, with its many unintended consequences, using data that were subsequently shown to be misleading. ${ }^{15}$ The updated analysis in the accompanying paper suggests that the increase is real but, crucially, the authors note "to assume that they are avoidable would be rash and misleading" and suggest a range of possible explanations. ${ }^{6}$ Given the changing nature of medicine some changes to working patterns are probably necessary, but it would be useful to have a better understanding of the reasons for any increase in deaths at weekends, details of what is being proposed, and evidence to justify any changes.

Competing interests: I have read and understood BMJ policy on declaration of interests and have no relevant interests to declare.
Provenance and peer review: Commissioned; not externally peer reviewed.

1 Jeremy Hunt: "We have 6000 avoidable deaths every year." BBC News 2015 Jul 16. www.bbc.co.uk/news/health-33546800.

2 Smith M. \#ImInWorkJeremy: Only a handful of doctors actually opt out of working weekends. Daily Mirror 2015 Jul 28. www.mirror.co.uk/news/uk-news/iminworkjeremyonly-handful-doctors-actually-6153084.

3 Triggle N. Jeremy Hunt: doctors "must work weekends." BBC News 2015 Jul 16. www. bbc.co.uk/news/health-33542940.

4 Freemantle N, Richardson M, Wood J, et al. Weekend hospitalization and additional risk of death: an analysis of inpatient data. J R Soc Med 2012;105:74-84.

5 Department of Health. Higher risk of death associated with weekend hospitalisation. 2015 www.gov.uk/government/publications/higher-risk-of-death-associated-with-weekendhospitalisation.

6 Freemantle N, Ray D, McNulty D, et al. Increased mortality associated with weekend hospital admission: a case for expanded seven day services? BMJ 2015;351:h4596.

7 UK Statistics Authority. Code of practice for official statistics. UK Statistics Authority, 2009.

8 Cunningham SA, Mitchell K, Narayan KM, Yusuf S. Doctors' strikes and mortality: a review. Soc Sci Med 2008;67:1784-8.

9 Salas M, Hofman A, Stricker BH. Confounding by indication: an example of variation in the use of epidemiologic terminology. Am J Epidemiol 1999;149:981-3.

10 Laughlin A, Parsons M, Kosloski KD, Bergman-Evans B. Predictors of mortality following involuntary interinstitutional relocation. J Gerontol Nurs 2007;33:20-6; quiz 8-9.

11 Wolff $A$, Stuckler $D$, McKee M. Are patients admitted to hospitals from care homes dehydrated? A retrospective analysis of hypernatraemia and in-hospital mortality. $J R$ Soc Med 2015;108:259-65.

12 Morris S, Hunter RM, Ramsay Al, et al. Impact of centralising acute stroke services in English metropolitan areas on mortality and length of hospital stay: difference-in-differences analysis. BMJ 2014;349:g4757.

13 Bray BD, Ayis S, Campbell J, et al. Associations between stroke mortality and weekend working by stroke specialist physicians and registered nurses: prospective multicentre cohort study. PLoS Med 2014;11:e1001705.

14 Meacock R, Doran T, Sutton M. What are the costs and benefits of providing comprehensive seven-day services for emergency hospital admissions? Health Econ 2015;24:907-12.

15 Appleby J. Does poor health justify NHS reform? BMJ 2011;342:d566

Cite this as: BMJ 2015;351:h4723

(C) BMJ Publishing Group Ltd 2015 